Supplement of Atmos. Chem. Phys., 15, 8577-8596, 2015

http://www.atmos-chem-phys.net/15/8577/2015/

doi:10.5194/acp-15-8577-2015-supplement

(C) Author(s) 2015. CC Attribution 3.0 License.

(c) (i)

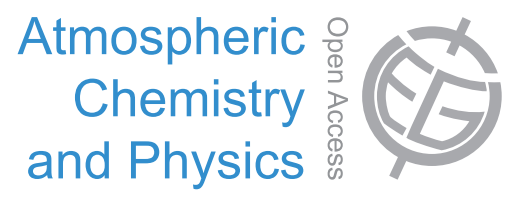

Supplement of

\title{
Uncertainties in global aerosols and climate effects due to biofuel emis- sions
}

\section{J. K. Kodros et al.}

Correspondence to: J. K. Kodros (jkodros@atmos.colostate.edu)

The copyright of individual parts of the supplement might differ from the CC-BY 3.0 licence. 

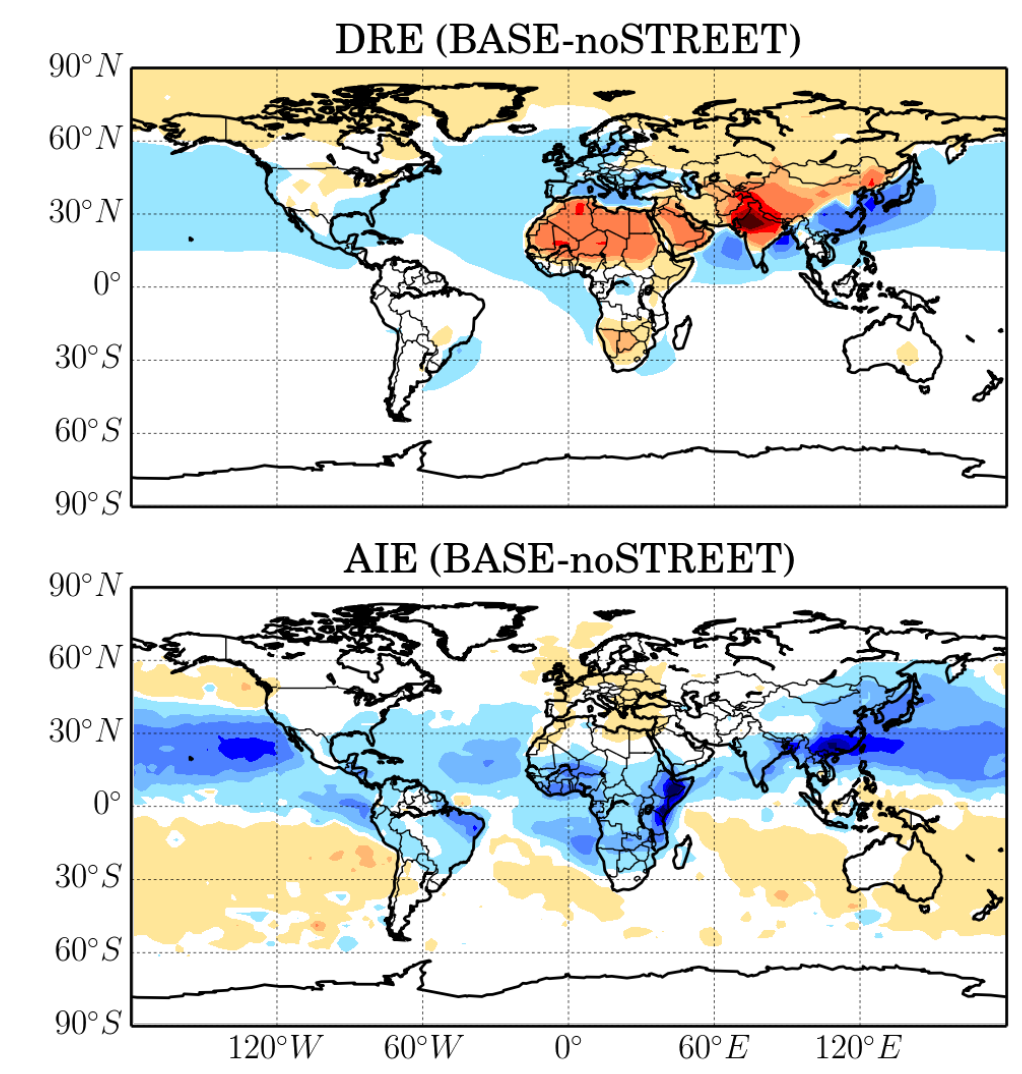

3 Figure S1. The DRE assuming a core-shell morphology (top, mean: $0.002 \mathrm{~W} \mathrm{~m}^{-2}$ ) and the AIE 4 (bottom, mean: $-0.019 \mathrm{~W} \mathrm{~m}^{-2}$ ) for the BASE-noSTREET comparison. 

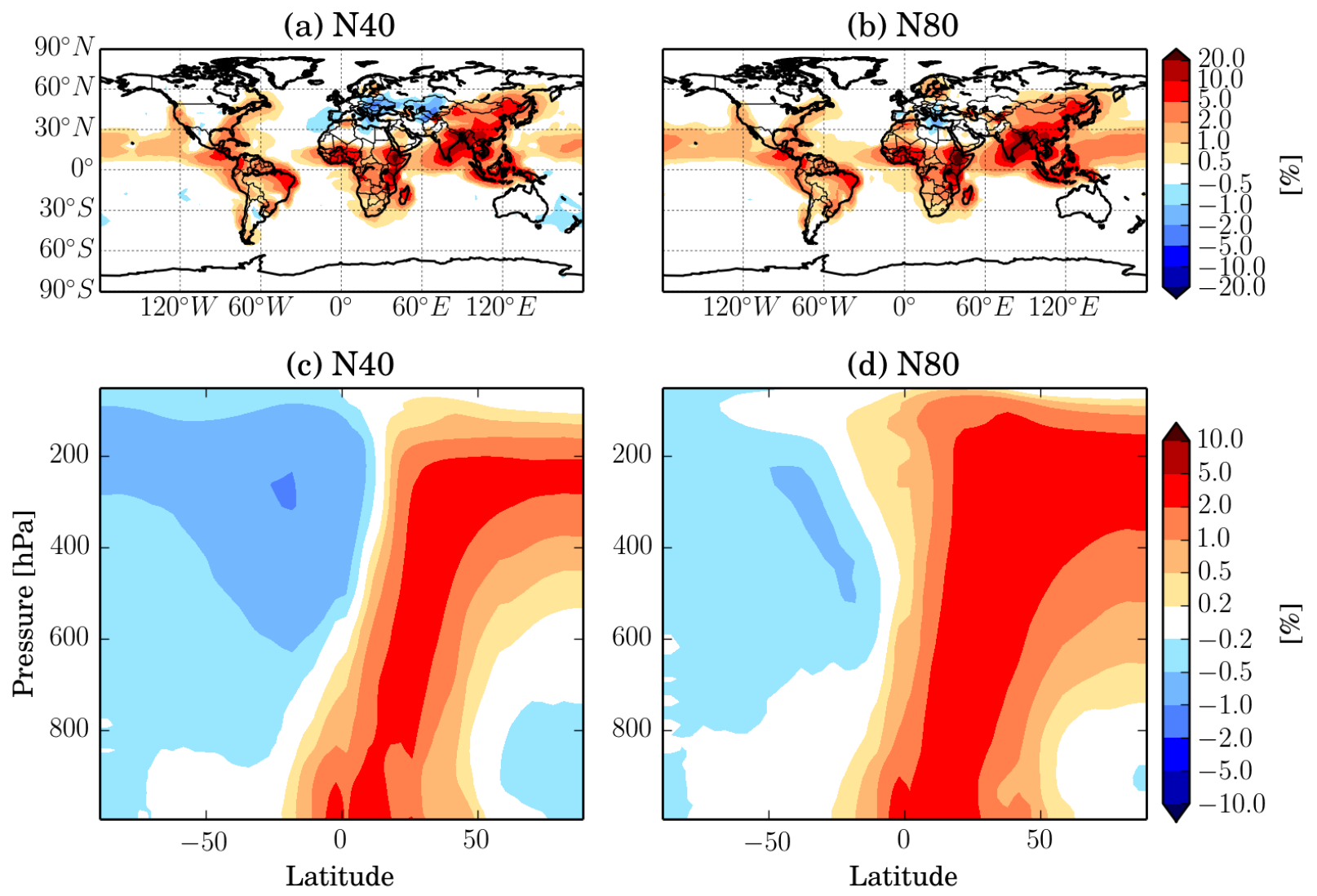

1

2 Figure S2. The percent change for the BASE-noSTREET comparison in boundary layer (a) N40 3 and (b) N80 and (c and d) zonally-averaged with height. 